Síntese: Revista de Filosofia adere a uma Licença

\title{
O TRÁGICO NO JOVEM NIETZSCHE: DA ESTÉTICA DA TRAGÉDIA À AUTOSSUPRESSÃO DO ESCLARECIMENTO FILOSÓFICO
}

\author{
The tragic in the young Nietzsche: from the aesthetics of tragedy \\ to the self-suppression of philosophical enlightenment
}

Wander Andrade de Paula *

Resumo: o principal objetivo do presente artigo é investigar o estatuto do 'trágico' no interior do pensamento de juventude de Friedrich Nietzsche. A partir de uma análise minuciosa dos diversos aspectos que o termo comporta nesse período de sua produção, especialmente no tratamento que é dedicado ao tema de Sócrates e do socratismo em $O$ nascimento da tragédia, desenvolvo a hipótese de que há uma importante diferença entre a estética do trágico na tragédia grega antiga e o caráter trágico da própria filosofia, tal como o autor os compreende. Desse modo, pretendo demonstrar que o conceito funcionou, muito antes de sua tardia noção de 'filosofia trágica', como um dispositivo teórico fundamental não apenas na sua crítica à tradição filosófica ocidental, como também, e sobretudo, na elaboração de sua própria concepção de filosofia.

Palavras-chave: Nietzsche. Tragédia. Trágico. Pessimismo. Esclarecimento. Autossupressão.

Abstract: the main purpose of this paper is to investigate the status of 'tragic' within young Friedrich Nietzsche's thinking. From a thorough analysis of the various aspects that the term entails in this period of his production, especially in his treatment of the theme of Socrates and Socratism in The birth of tragedy, I develop the hypothesis that there is an important difference between the aesthetics of the tragic in ancient Greek tragedy and the tragic character

* Doutor em Filosofia. Professor do Departamento de Filosofia da Universidade Federal do Espírito Santo. Artigo recebido em 03/04/2019 e aprovado para publicação em 04/10/2019. 
of philosophy itself, as the author understands them. In this way, I intend to demonstrate that the concept worked, long before his belated notion of 'tragic philosophy', as a fundamental theoretical device not only in his critique of the Western philosophical tradition, but also, and above all, in the elaboration of his own conception of philosophy.

Keywords: Nietzsche. Tragedy. Tragic. Pessimism. Enlightenment. Self-suppression.

\section{A recepção do problema do trágico pelo pensamento alemão do XVIII e XIX}

1 s primeiras formulações do trágico como problema filosófico datam do pensamento de Górgias, ocasião em que a tragédia se torna objeto de reflexão filosófica, e é concebida como paradigma do poder de convencimento do logos retórico. Essa tendência continua presente no pensamento de Platão, dado que o pensador grego trata da tragédia também no contexto da retórica, mas sobretudo concebe a poesia como uma espécie de afetividade inferior, razão pela qual os afetos trágicos deveriam ser subordinados à filosofia, "a tragédia mais verdadeira": "o trágico alcança uma função positiva apenas na medida em que a retórica for fundamentada por meio do conhecimento filosófico da dialética" ${ }^{1}$. É a Aristóteles que coube, contudo, a formulação clássica do problema da tragédia e do trágico na Poética, momento em que o tema não é discutido mais no contexto da retórica, mas das ciências poéticas:

É pois a tragédia a mimese de uma ação de caráter elevado, completa e de certa extensão, em linguagem ornamentada, com cada uma das espécies de ornamento distintamente distribuídas em suas partes; mimese que se efetua por meio de ações dramatizadas e não por meio de uma narração, e que, em função da compaixão e do pavor, realiza a catarse de tais emoções ${ }^{2}$.

O objetivo da tragédia passa a ser compreendido, então, como a representação do trágico, que por sua vez consiste em uma excitação das paixões do pavor (ou medo, phóbos) e da compaixão, denominadas pelo autor como o "pathos trágico". A tragédia constitui, portanto, para Aristóteles, uma espécie de representação da excitação do pathos trágico, tendo em vista sua purificação, sua "catarse" ${ }^{3}$.

Ainda que o problema do trágico apareça de modo esparso na obra de alguns autores ao longo da história da filosofia, a formulação aristotélica é a que parece perdurar e servir de base por muitos séculos. Prova disso

\footnotetext{
${ }^{1}$ LOOCK, R. Tragische. In: Historisches Wörterbuch der Philosophie, Bd. 10: St-T. Hrg. von Joachim Ritter et all. Basel: Schwabe, 1998. Col. 1334-1345. Cf. cols. 1334-1335.

${ }^{2}$ ARISTÓTELES. Poética. Tradução de Paulo Pinheiro. São Paulo: Editora 34, 2015. 1449b25.

${ }^{3}$ LOOCK, R. Tragische. In: Historisches Wörterbuch der Philosophie, Bd. 10: St-T. Hrg. von Joachim Ritter et all. Basel: Schwabe, 1998. Col. 1334-1345. Cf. cols. 1335-1336.
} 
é que a discussão em torno do tema volta a ganhar fôlego apenas no fim do século XV e início do XVI, precisamente com a publicação de novas traduções da Poética ${ }^{4}$. As implicações desse processo podem ser notadas em autores do século XVII, como Pierre Corneille e Jean Racine, mas encontram sua formulação filosófica mais bem elaborada no século XIX alemão, em autores como Schelling, Hegel, Hölderlin, e muito especialmente Schopenhauer e Nietzsche ${ }^{5}$.

A cena intelectual da Alemanha do período em questão é marcada por algumas particularidades importantes, que parecem diretamente relacionadas com a sua preocupação filosófica com o problema do trágico. Michael Pauen afirma que há uma espécie de "fascinação pelo terrível" (Faszination des Schrecklichen) na literatura, cujo "poder de atração" (Anziehungskraft) é marcado por um "diagnóstico do terrível", uma "estética do horror [Grauen]" e a uma "interpretação pessimista da realidade"6. Rüdiger Safranski, por seu turno, destaca que há uma "atmosfera pessimista" no romantismo, a qual manifesta, para tomarmos um exemplo paradigmático, nas discussões de Schiller sobre o papel da arte e da literatura na libertação do homem, o teor crítico desse movimento em relação ao iluminismo e à ciência, sendo estes compreendidos como frutos de uma mera cultura teórica, que dissimula a barbaridade inerente ao homem. A essa desconfiança em relação ao espírito do iluminismo corresponde, nos românticos, a paixão pelo obscuro, pelo enigmático, pelo monstruoso, aspectos que caracterizam a vida em sua profundidade, dando espaço para a melancolia ${ }^{7}$. Ademais, são autores românticos que ampliam, desenvolvem e secularizam o entendimento da melancolia (até o século XVIII compreendida apenas como uma patologia), vinculando-a profundamente às noções de gênio artístico (artistic genius) e paisagem (landscape), ao mesmo tempo em que a distanciam da interpretação religiosa tradicional dos sofrimentos da melancolia. Desse modo, a melancolia é transformada no romantismo em um "espírito produtivo" (productive mood) ${ }^{8}$. A crítica à razão levada a cabo pelos românticos tinha como alvo, em suma, a defesa do lado misterioso da existência, como resposta imediata à redução iluminista do mundo a um mecanismo?.

\footnotetext{
${ }^{4}$ LOOCK, R. Tragische. In: Historisches Wörterbuch der Philosophie, Bd. 10: St-T. Hrg. von Joachim Ritter et all. Basel: Schwabe, 1998. Col. 1334-1345. Cf. cols. 1336-1337.

${ }^{5}$ Cf. MACHADO, Roberto. O Nascimento do Trágico: de Schiller a Nietzsche. Rio de Janeiro: Jorge Zahar, 2006.

6 PAUEN, Michael. Pessimismus. Geschichtsphilosophie, Metaphysik und Moderne von Nietzsche bis Spengler. Berlin: Akademie Verlag, 1997. Cf. p. 86-102). Notáveis são, nesse contexto, segundo Pauen, as obras de Ernst August Klingemann, M. Solitaire (i. e. Woldemar Nürnberger) e Joris-Karl Huysmans, mas também de autores consagrados como Charles Baudelaire e Edgar Allan Poe.

7 SAFRANSKI, Rüdiger. Romantismo: uma questão alemã. Tradução de Rita Rios. São Paulo: Estação Liberdade, 2010. Cf. p. 41-42 e p. 51-52.

${ }^{8}$ Cf. MITCHELL, R. "Melancholy". In: Encyclopedia of the Romantic Era, 1760-1850. Vol. II. Ed. Ch. J. Murray. New York; London: Fitzroy Dearborn, p. 722-723.

9 SAFRANSKI, Rüdiger. Romantismo: uma questão alemã. Tradução de Rita Rios. São Paulo: Estação Liberdade, 2010. Cf. p. 177-190.
} 
Influenciados diretamente pelos desdobramentos do iluminismo tanto na crítica kantiana quanto no movimento romântico alemão, Schopenhauer e Nietzsche estão comprometidos com dois problemas filosóficos diretamente vinculados entre si e também à tal cena intelectual alemã: o trágico e o pessimismo ${ }^{10}$. Alçado a tema filosófico precisamente por Schopenhauer e pela recepção da sua obra por autores como Eduard von Hartmann, Eugen Dühring e o próprio Nietzsche, o pessimismo discute fundamentalmente o problema do sentido da vida: há uma justificação para a existência? ${ }^{11}$. A resposta a essa questão constitui um dos pilares de sustentação dos projetos filosóficos de ambos autores. O pensamento de juventude de Nietzsche, objeto do presente artigo, é um dos exemplos paradigmáticos desse modo de proceder filosófico, ao tratar do tema do trágico em meio às suas discussões sobre o problema do pessimismo. Ainda que o enfoque deste artigo recaia na sua interpretação do trágico em suas primeiras reflexões filosóficas, espero demonstrar a relevância do tema do pessimismo nesse contexto e, principalmente, indicar os desdobramentos dessas discussões para a própria concepção nietzscheana de filosofia.

\section{O trágico em Nietzsche: o que nos diz a fortuna critica}

Uma tese quase hegemônica a respeito de $O$ nascimento da tragédia, primeira obra publicada por Nietzsche, é a de que o filósofo nos apresenta uma concepção metafísica do trágico, por meio da qual ele descreve a essência da existência como enigmática, conflituosa e fundamentalmente sofredora. Em virtude disso, o problema do trágico aparece sempre vinculado, senão circunscrito, ao problema colocado pelo pessimismo filosófico, que, conforme

\footnotetext{
${ }^{10}$ É fundamental compreender, de antemão, que o pessimismo filosófico não é uma espécie de reverberação das condições históricas em que ele surge, conforme nos esclarece, por exemplo, Michael Pauen, ao objetar a "hipótese da crise" (Krisehypothese) (PAUEN, Michael. Pessimismus. Geschichtsphilosophie, Metaphysik und Moderne von Nietzsche bis Spengler. Berlin: Akademie Verlag, 1997. Cf. esp. p. 08-09; 19-25; 113-117). O problema do pessimismo é, a meu ver, fruto de uma crise no interior da própria filosofia, uma crise que diz respeito ao próprio modo de proceder filosófico. E, nesse sentido, a reinterpretação nietzscheana do tema, como uma resposta especialmente ao pensamento de Schopenhauer, demonstra o quanto o filósofo alemão tem como compromisso levar adiante essa tese (cf. DE PAULA, Wander Andrade. Nietzsche e a transfiguração do pessimismo schopenhaueriano. A concepção de filosofia trágica. Tese de Doutorado. Campinas: Universidade Estadual de Campinas, 2013). ${ }^{11}$ Cf. GERHARDT, V. Pessimismus. In: Historisches Wörterbuch der Philosophie, Bd. 7: P-Q. Hrg. von Joachim Ritter et all. Basel und Darmstadt, 1989a. Col. 386-395; DAHLKVIST, Tobias. Nietzsche and the Philosophy of Pessimism. A study of Nietzsche's Relation to the Pessimistic Tradition: Schopenhauer, Hartmann, Leopardi. Uppsala: Uppsala Studies in History of Ideas 35, 2007; DE PAULA, Wander Andrade. Nietzsche e a transfiguração do pessimismo schopenhaueriano. A concepção de filosofia trágica. Tese de Doutorado. Campinas: Universidade Estadual de Campinas, 2013.
} 
indicado anteriormente, Nietzsche herda e reinterpreta do pensamento de Schopenhauer e da tradição filosófica dita "pessimista" que lhe segue ${ }^{12}$.

Nietzsche demonstra, de fato, grande interesse pelo estudo da tragédia grega desde muito cedo, quando, por exemplo, ainda como estudante da prestigiosa escola de Pforta, redige, em 1864, um ensaio sobre o primeiro coro do Édipo Rei. É atestada nas anotações pessoais que precedem a publicação de sua primeira obra uma genuína preocupação com a definição do trágico, ocasião em que o autor se questiona: "o trágico exprime a forma mais geral da existência?"13. Ainda que não a responda na sequência do texto, o autor fornece subsídios para uma melhor compreensão de sua concepção do trágico:

O trágico pode ser somente uma intensificação [Steigerung] do lírico: em oposição ao épico. A dissolução da música em um mito é o trágico. O mito trágico se comporta em relação à lírica da mesma forma que a epopeia em relação à pintura (...). O mito trágico [é, W.P.] a representação de um sofrer como interpretação da música (...). O especialmente dramático não pertence à essência do trágico (...). O coro trágico vê o mito como o rapsodo [vê, W.P.] a epopeia ${ }^{14}$.

Nietzsche parece lançar mão de uma determinada concepção de trágico para qualificar suas diversas manifestações ${ }^{15}$. Mas que concepção de trágico é essa, uma vez que encontramos apenas indícios de como ela deve ser entendida - e não uma definição da mesma -, tanto em suas anotações quanto em seus demais textos privados e publicados?

Um considerável número de intérpretes procurou trazer luz a esse intrigante tema da filosofia de juventude de Nietzsche, que encontra importantes ecos em seu pensamento posterior. Partindo do debate entre Lyotard e Habermas sobre o lugar do filósofo alemão na estética da pós-modernidade, Nuno Nabais defende, em texto do final da década de 1990, que $O$ nascimento da tragédia tem como precursores imediatos a leitura schilleriana da Crítica da faculdade do juízo e as estéticas de Schopenhauer e de Wagner,

${ }^{12}$ DAHLKVIST, Tobias. Nietzsche and the Philosophy of Pessimism. A study of Nietzsche's Relation to the Pessimistic Tradition: Schopenhauer, Hartmann, Leopardi. Uppsala: Uppsala Studies in History of Ideas 35, 2007. Cf. p. 62-77.

${ }^{13}$ NIETZSCHE, F. Anotação póstuma 9[125], 1871. In: KSA 7, p. 320. Cf., ainda, por exemplo, as anotações 5[122], Setembro de 1870 - Janeiro de 1871. KSA 7, p. 127; e 7[64], Fim de 1870 - Abril de 1871. KSA 7, p. 153.

${ }^{14}$ NIETZSCHE, F. Anotação póstuma 9[125], 1871. In: KSA 7, p. 320-321.

${ }^{15}$ Encontramos, somente em $O$ nascimento da tragédia, os seguintes substantivos qualificados com o adjetivo "trágico" (tragisch): Mythus (caps. 16, 17, 21, 22, 24 e 25), Chor (7 e 8), Held $(8,10,11,12,21$ e 22), Bühne (10, 12), Gestalten (10), Zuschauer (21), Dichtung (10), Dichter (11), Kunst (8, 11, 13, 14, 15 e17), Künstler (22 e 24), Kunstwerk (17), Kunstbedürftigkeit (16), Weltbetrachtung (16 e 17), Erkenntniss (15), Cultur (18), Mensch (18 e 20), Wirkung (12, 22 e 24), Resignation (15), Situation (22), Dissonanz (17), Zeitalter (19), Mysterien (21), Symbolik (16) e Mitleiden (14). 
cuja radicalização da diferença entre uma estética do belo e uma estética do sublime marcam o projeto de filosofia nietzscheano. Sob esse ponto de vista, a duplicidade Apolo e Dionísio só pode ser bem compreendida como análoga das categorias kantianas do belo e do sublime, respectivamente. A ideia de uma condição sublime da tragédia e, por conseguinte, do trágico deve ser buscada a partir desse ponto de vista ${ }^{16}$.

Peter Szondi já havia apresentado, em texto clássico de 1961 sobre o assunto, os conceitos de tragicidade (Tragik) e trágico (Tragisch) como essencialmente germânicos, sustentando que uma "filosofia do trágico" surge apenas com Schelling, momento em que se rompe com o modelo clássico de interpretação "poetológica" da tragédia. Inaugurada pela Poética de Aristóteles, essa última forma de interpretação preocupa-se apenas em descrever os elementos constituintes da tragédia. Para Szondi, os conceitos schopenhauerianos de vontade e representação são os antepassados dos princípios artísticos nietzscheanos do dionisíaco e do apolíneo, respectivamente, e é a partir desse ponto de vista que ele vai tratar do tema do trágico em Nietzsche: como o permanente conflito entre o dionisíaco e o apolíneo ${ }^{17}$.

Dentre os intérpretes brasileiros, Roberto Machado parece ser aquele que, em diálogo com os autores supracitados, se compromete mais decididamente em levar adiante a tese de que entre os alemães surge uma interpretação ontológica da tragédia. $\mathrm{O}$ autor demonstra, em texto datado de 2006, que se, por um lado, o tratamento dedicado ao tema do trágico por autores como Goethe, Schiller, Winckelmann e Lessing evidencia o esforço de formação de um teatro nacional alemão, por outro, Schelling, Hegel, Hölderlin, Schopenhauer e Nietzsche inauguram, de fato, uma "ontologia do trágico" - e, por conseguinte, demarcam a ruptura com as interpretações "poetológicas" da tragédia. A concepção nietzscheana de trágico é interpretada por Machado a partir da noção de um conflito dialético, solucionado com a tragédia, entre as pulsões apolínea e dionisíaca. E, adotando a sugestão de Nabais e Szondi, também as concebe como correlatas das noções kantianas de belo e sublime e das noções schopenhauerianas de vontade e representação ${ }^{18}$.

\footnotetext{
${ }^{16}$ NABAIS, Nuno. Metafísica do trágico. Estudos sobre Nietzsche. Lisboa: Relógio D'Água, 1997. Cf. p. 17-71.

${ }_{17}$ SZONDI, P. Ensaio sobre o trágico. Tradução de Pedro Süssekind. Rio de Janeiro: Jorge Zahar, 2004. Cf. p. 67-69.

${ }^{18}$ Cf. MACHADO, Roberto. O Nascimento do Trágico: de Schiller a Nietzsche. Rio de Janeiro: Jorge Zahar, 2006. É importante salientar que essa interpretação acerca do modo com que Aristóteles lida com a tragédia não é hegemônica. Autores como Albin Lesky e Jacqueline de Romilly defendem que há, no pensamento do filósofo grego, uma tentativa de definir o trágico, que vai bem além de uma mera análise técnica da tragédia grega (LESKY, A. A tragédia grega. Tradução de J. Guinsburg. São Paulo: Perspectiva, 2006. Cf. p. 27-29; ROMILLY, J. A tragédia grega. Tradução de Leonor Santa Bárbara. Lisboa, Portugal: Edições 70, 2013. Cf. p. 17-20). Importante menção deve ser feita também ao texto de Enrico Müller, que, dentre os intérpretes de Nietzsche mais recentes, segue nessa mesma direção argumentativa. Para Müller, a concepção nietzscheana de trágico, sustentada pelas noções de "prazer estético"
} 
Em obra fundamental de 1981 dedicada à interpretação nietzscheana da tragédia, Silk e Stern já haviam discutido o problema do trágico no pensamento do filósofo alemão em termos de uma dialética entre o apolíneo e o dionisíaco. Os autores tocam, entretanto, no cerne do problema do trágico em uma tese, a meu ver, não suficientemente desenvolvida em sua obra. Ao nos alertarem para a diferença entre "efeito trágico" (tragische Wirkung) e "atitude trágica" (das Tragische), eles defendem que a concepção nietzscheana de trágico está circunscrita à sua interpretação do drama:

Pode a poesia lírica produzir o efeito trágico? Ou somente a atitude trágica (das Tragische)? Até que ponto pode ser dito que o efeito sobre uma audiência se segue da representação de uma atitude? Pode até mesmo a épica servir de veículo? (...) Certamente, em virtude de ser drama, a tragédia está comprometida em causar um impacto que difere daquele de outras formas. Mas outras formas podem conter 'o trágico' e, em sua negação desse aspecto, O nascimento da tragédia é simplesmente muito esquemático ${ }^{19}$.

A tese de Silk e Stern é a de que o capítulo 16 de O nascimento da tragédia, mais particularmente a sentença "(...) e onde mais haveremos de buscar tal expressão senão na tragédia e, em geral, no conceito do trágico?", representa quase, mas não efetivamente, "um passo crucial que significaria o abandono de sua tentativa de definir a tragōidia grega e a concentração em uma tentativa de definir 'o trágico' em seu lugar" ${ }^{20}$. Os autores defendem, desse modo, que a definição nietzscheana de trágico está circunscrita à sua interpretação da tragédia grega, mas, ao mesmo tempo, indicam que o filósofo alemão quase abandona o projeto de definição da tragédia para se concentrar no trágico.

O presente artigo tem por objetivo central demonstrar, contra Silk e Stern e os demais autores supracitados, que a concepção de trágico em $O$ nascimento da tragédia é mais ampla do que aquela porventura extraída das análises nietzscheanas da tragédia grega antiga. Ao desenvolver a tese de que também, e sobretudo, em suas análises de Sócrates e do socratismo há um aspecto fundamental de sua definição de trágico, espera-se discutir os pressupostos de sua concepção inicial de filosofia, de modo que fique

e "sabedoria dionisíaca", é uma espécie de resposta à interpretação aristotélica da catarse. Esse ponto de vista tem importantes implicações: a primeira é que Müller não leva adiante a tese de que em Aristóteles haja apenas uma análise "poetológica" da tragédia; a segunda é que a interpretação nietzscheana do trágico está imediatamente comprometida, no seu ponto de vista, com uma resposta à concepção aristotélica do mesmo; a terceira é que o autor concentra a sua interpretação do trágico em Nietzsche predominantemente a partir da sua interpretação da tragédia grega (MÜLLER, Enrico. Die Griechen im Denken Nietzsches. Berlin/New York: Walter de Gruyter, 2005 [Monographien und Texte zur Nietzsche-Forschung, Band 50]. Cf. p. 35-54).

${ }^{19}$ SILK, M. S; STERN, J. P. Nietzsche on tragedy. New York: Cambridge University Press, 1981, p. 278. Cf. também p. 279 e p. 265-266.

${ }^{20}$ SILK, M. S; STERN, J. P. Nietzsche on tragedy. New York: Cambridge University Press, 1981, p. 279. 
comprovado que o estatuto do "esteticismo" do jovem Nietzsche, caso tal definição ainda se mostre adequada ao fim do presente texto, é bem mais multifacetado e complexo do que se convencionou nas discussões da fortuna crítica ${ }^{21}$.

\section{Aspectos e variantes do trágico no jovem Nietzsche}

\section{1. $\mathrm{O}$ aspecto metafísico}

Um dos contextos mais relevantes do tema do trágico em Nietzsche é a sua discussão acerca da espécie de retorno do homem à natureza causado pela tragédia. Ao tratar do "superpotente sentimento de unidade que reconduz ao coração da natureza" como o "efeito mais imediato da tragédia dionisíaca" e do consolo metafísico por ela proporcionado - "de que a vida, no fundo das coisas, apesar de toda mudança das aparências fenomenais, é indestrutivelmente poderosa e cheia de alegria" -, Nietzsche remete-nos imediatamente, ao utilizar expressões como "coração da natureza" e "no fundo das coisas", a uma concepção essencialista da existência. Tal concepção tem por intuito apresentar o heleno como aquele que é "singularmente apto ao mais terno e ao mais pesado sofrimento", pois somente ele consegue perceber a "terrível ação destrutiva da assim

\footnotetext{
${ }^{21}$ Deve-se destacar que a dificuldade de definir o trágico não concerne apenas à filosofia, tampouco ao pensamento de Nietzsche. Albin Lesky, por exemplo, viu a necessidade de acrescentar, cerca de 20 anos após a publicação de sua obra clássica sobre a tragédia grega, um capítulo introdutório dedicado especialmente ao problema do trágico e à dificuldade de sua definição. Partindo das palavras de Goethe, para quem "todo trágico se baseia numa contradição inconciliável", Lesky encontra quatro requisitos imprescindíveis para o "aparecimento do efeito trágico": i) a "dignidade" e a "considerável altura da queda", que consiste numa espécie de "queda de um mundo ilusório de segurança e felicidade para o abismo da desgraça ineludível (...) num decurso de acontecimentos de intenso dinamismo"; ii) a "possibilidade de relação com nosso próprio mundo", no sentido de que "o caso deve interessar-nos, afetar-nos, comover-nos"; iii) o fato de que o "sujeito do ato trágico (...) deve ter alçado à sua consciência tudo isso e sofrer tudo conscientemente"; iv) e deve também constituir, conforme indicado anteriormente, em uma "contradição inconciliável". O grande impasse levantado pelo último requisito é, segundo o autor, que muitas tragédias possuem soluções conciliadoras - dentre elas a Oréstia, de Ésquilo, uma das maiores criações da tragédia grega. Lesky propõe, então, uma distinção conceitual básica para solucionar tal problema, de modo a esclarecer os diferentes usos do 'trágico' na tragédia grega antiga: i) a "visão cerradamente trágica do mundo" consiste em uma tentativa de interpretação do todo do universo, a partir do trágico; ii) no "conflito trágico cerrado", definição que se aproximaria daquela de Goethe, manifesta-se um conflito que, por mais fechado que seja em si mesmo no seu decurso, não diz respeito ao todo do universo; iii) para a "situação trágica", por fim, a falta de escapatória não é definitiva (LESKY, A. A tragédia grega. Tradução de J. Guinsburg. São Paulo: Perspectiva, 2006. Cf. p. 31-38). Perceba-se como a discussão que envolve o trágico ainda gera grandes dificuldades na discussão especializada sobre o tema, obrigando pesquisadores a ampliarem seu escopo conceitual, o que implica em uma definição mais abrangente e nuançada do mesmo.
} 
chamada história universal" e a "crueldade da natureza"22. A concepção de que o sofrimento é essencial à existência provém, portanto, do conhecimento de sua realidade, que só pode ser transfigurada e justificada, como Nietzsche defende na obra em questão, pela arte:

Nesse sentido, o homem dionisíaco se assemelha a Hamlet: ambos lançaram alguma vez um olhar verdadeiro à essência das coisas, ambos passaram a conhecer e a ambos enoja atuar; pois sua atuação não pode modificar em nada a eterna essência das coisas (...). O conhecimento mata a atuação, para atuar é preciso estar velado pela ilusão (...); não é o refletir, não, mas é o verdadeiro conhecimento, o relance interior na horrenda verdade, que sobrepesa todo e qualquer motivo que possa impelir à atuação, quer em Hamlet quer no homem dionisíaco. Na consciência da verdade uma vez contemplada, o homem vê agora, por toda parte, apenas o aspecto horroroso e absurdo do ser (...), agora reconhece a sabedoria do deus dos bosques, Sileno: isso o enoja ${ }^{23}$.

A partir de tal concepção essencialista da existência, Nietzsche sugere que o sofrimento que lhe caracteriza está amparado em algo que possui realidade e lhe é anterior. A "sabedoria dionisíaca", a "sabedoria do sofrimento", expressa precisamente a contradição, a dor e o sofrimento que caracterizam a existência. O sátiro, "enquanto anunciador da sabedoria que sai do seio mais profundo da natureza", da "verdade da natureza", manifesta a "única realidade" que constitui o "eterno cerne das coisas, a coisa em si" ${ }^{24}$. Ainda que Nietzsche pareça se valer apenas estrategicamente do conceito de coisa em si nesse contexto, o principal da concepção em questão é que o trágico está relacionado a uma tentativa de descrição de nossa condição existencial básica, enquanto seres humanos. Esta é a razão pela qual considero essa a variante ontológica do aspecto metafísico do trágico.

Caudatária, e ao mesmo tempo subsumida à variante que acabo de discutir, é a discussão nietzscheana sobre a relação entre a tragédia e o trágico, especialmente no que diz respeito aos efeitos (Wirkungen) provocados na arte apolínea pela música dionisíaca: se, por um lado, a música dionisíaca "estimula à introvisão similiforme [gleichnissartigen Anschauen] da universalidade dionisíaca", por outro, ela permite que "a imagem similiforme emerja com suprema significatividade". É desse duplo efeito por ela causado

\footnotetext{
${ }^{22}$ GT/NT, 7. KSA 1, p. 56. Seguindo as diretrizes da Nietzsche-Forschung (pesquisa Nietzsche) internacional, $O$ nascimento da tragédia é mencionado, doravante, por meio das siglas GT/NT, que remetem aos seus títulos em alemão e português, respectivamente. As siglas são seguidas pelo número do capítulo da obra e pela referência à Kritische Studienausgabe (KSA), edição de estudos que compila as obras publicadas e as anotações pessoais do autor entre os anos de 1869 e 1889. A tradução utilizada é a de Jacó Guinsburg, publicada pela Companhia das Letras, que em algumas ocasiões é alterada, com a devida indicação.

${ }^{23}$ GT/NT, 7. KSA 1, p. 56-57.

${ }^{24}$ GT/NT, 8. KSA 1, pp. 58-9. “(...) e assim como a tragédia, com o seu consolo metafísico, aponta para a vida perene daquele cerne da existência, apesar da incessante destruição das aparências, do mesmo modo o simbolismo do coro satírico já exprime em um símile a relação primordial entre coisa em si e fenômeno" (GT/NT, 8. KSA 1, p. 59).
} 
que Nietzsche deduz a sua capacidade "para dar nascimento ao mito, isto é, o exemplo significativo, e precisamente o mito trágico: o mito que fala em símiles [Gleichnissen] acerca do conhecimento dionisíaco" ${ }^{25}$. Torna-se necessário, nesse processo, que a música entoada pelo coro satírico atinja uma suprema afiguração (höchste Verbildlichung), uma "expressão simbólica para a sua autêntica sabedoria dionisíaca", que deve ser buscada, segundo Nietzsche, "na tragédia e, em geral, no conceito do trágico"26.

Percebe-se, portanto, o papel central da música na definição do trágico, quando considerado sob o ponto de vista estético: é ela que nos permite compreender a "alegria no aniquilamento do indivíduo". Por meio da música, e, por conseguinte, da tragédia, pode-se ter acesso à verdade dionisíaca de que a vida é em si essencialmente sofrimento, sem que essa verdade seja patológica. Essa definição se faz presente em várias anotações pessoais do filósofo, com destaque para uma em que ele pondera que a visão trágica de mundo (tragische Weltansicht) é como um "ponto-limite" (Grenzpunkt), no qual "beleza e verdade se mantêm em equilíbrio", ao passo que a tragédia representa o momento em que ocorre a "vitória da beleza sobre o conhecimento" ${ }^{27}$.

A tragédia grega não é, contudo, o fenômeno trágico. A tragédia é, na verdade, a expressão de uma "consideração de mundo trágica" (tragische Weltbetrachtung): trágica seria, portanto, a condição essencial da existência como contradição, dor e sofrimento. $\mathrm{O}$ reconhecimento dos limites humanos constitui, por conseguinte, o pressuposto necessário da busca pela ilusão (Illusion) proporcionada pela arte ${ }^{28}$. Esse é o sentido da variante estética

${ }^{25}$ GT/NT, 16. KSA 1, p. 107.

${ }^{27}$ NIETZSCHE, F. Anotação póstuma 3[45], Inverno de 1869-70 - Início de 1870. KSA 7, p. 73Cf., nesse mesmo sentido, as seguintes anotações: 3[33], Inverno de 1869-70 - Início de 1870. KSA 7, p. 69; 7[128], Fim de 1870 - Abril de 1871. KSA 7, p. 192; 8[2], Inverno de 187071 - Outono de 1872. KSA 7, p. 219. Cf., ainda, sobre a relação entre a música e o trágico: 3[35], Inverno de 1869-70 - Início de 1870. KSA 7, p. 70; 3[41], Inverno de 1869-70 - Início de 1870. KSA 7, p. 72; 3[42], Inverno de 1869-70 - Início de 1870. KSA 7, p. 72; 7[174], Fim de 1870 - Abril de 1871. KSA 7, p. 206.

${ }^{28}$ Clademir Araldi parece estar, em parte, de acordo com essa concepção de trágico enquanto a necessidade de se utilizar da ilusão para encobrir a verdade (Wahrheit), a despeito da incompatibilidade entre elas. A tragédia, enquanto fenômeno artístico, não poderia ser considerada trágica na visão de Nietzsche, pois, segundo Araldi, ela surge precisamente no momento em que o apolíneo e o dionisíaco se encontram unidos. O processo que envolve a morte da tragédia e a conseguinte ascensão do racionalismo socrático também não poderia, de acordo com o autor, ser considerado como o trágico, uma vez que esse movimento não seria imanente à tragédia. Trágico, de acordo com Araldi, não seria nem o apolíneo e nem o dionisíaco, mas "o conflito insolúvel do indivíduo que luta e sofre com o curso inevitável do mundo, sem conseguir viver completamente nas aparências, e sem lograr a salvação no fatalismo dionisíaco, com suas dores e prazeres primordiais". Como se pode perceber, o autor entende que o trágico se define mais por esse "não-lugar" do homem na existência, uma vez que ele não pode viver completamente nem no dionisíaco e nem no apolíneo. Embora esteja em grande medida de acordo com Araldi, acredito que, pelos indícios que encontramos tanto 
do aspecto metafísico do trágico, razão pela qual ela é considerada como caudatária e subsumida à sua variante ontológica.

Importante figura de seu pensamento de juventude, o "homem trágico"29 é discutido por Nietzsche a partir do problema da relação entre verdade e ilusão. Enquanto "professor dos homens", compete-lhe uma "educação para o trágico" ${ }^{30}$, a qual

(...) pressupõe determinabilidade do caráter, livre decisão de escolha etc. para a Práxis, contudo, ela as contesta teoricamente e colocam este problema imediatamente no cume da educação. Nós nos comportaremos sempre assim como nós somos e jamais como nós devemos ser.

O gênio tem o poder de encapar com uma nova rede de ilusão: a educação para o gênio significa tornar a rede de ilusão necessária, através de uma diligente consideração da contradição.

O conhecimento trágico é também para a realidade no Uno-primordial [Ureinen-Wahren] somente uma representação, uma figura, um delírio [Wahn]. Mas na medida em que a contradição, quer dizer, aquilo que é inconciliável nessa figura, é visto - nós vivenciamos como que a cena do rapaz possuído exigida pela transfiguração. Ser educado - significa tão-somente - desdobrar-se [sich auseinander falten]. Mantém-se somente o deserto e o tormento do sagrado como pressuposição necessária para o êxtase [Verzückung] (...) $)^{31}$.

Essas discussões sobre o gênio ganham mais espaço em textos posteriores, sobretudo em algumas anotações pessoais, conforme será discutido, e em Schopenhauer como educador. No presente contexto, a educação para o trágico significa a busca pela forma mais adequada de se estabelecer a relação entre verdade e ilusão: trata-se, tal como indicado pela vertente estética do trágico, de encontrar na ilusão da arte uma forma privilegiada de lidar com a verdade. Essas reflexões dão ensejo à vertente cultural do aspecto metafísico do trágico, no sentido de que Nietzsche o compreende como base da formação cultural alemã.

A ideia que fundamenta a distinção entre as vertentes ontológica, estética e cultural do aspecto metafísico do trágico no jovem Nietzsche é a de que

nos textos publicados quanto nas suas anotações pessoais, Nietzsche parece pender mais para uma concepção de trágico enquanto uma necessidade de ilusão, dada a condição essencial da existência. ARALDI, Clademir. O conflito trágico entre arte e verdade no pensamento de Nietzsche. In: Revista Trágica, $2^{\circ}$ semestre de 2008 (n. 2), p. 37-52. Cf. p. 48.

${ }^{29}$ Trata-se de uma expressão bastante recorrente no pensamento do autor. Cf. as anotações póstumas: 5[94], 5[95], 5[96], 5[105], 5[108], 5[113], 5[114], Setembro de 1870 - Janeiro de 1871; 6[9], 6[11], Fim de 1870; 7[15], 7[35], 7[123], Fim de 1870 - Abril de 1871; 8[13], Inverno de 1870-71 - Outono de 1872; 9[36], 1871; 13[2], Início - Outono de 1871.

${ }^{30}$ Cf. anotações póstumas 5[105], 5[106] e 5[107], Setembro de 1870 - Janeiro de 1871. KSA 7, p. 121; 7[143], Fim de 1870 - Abril de 1871. KSA 7, p. 196.

${ }^{31}$ NIETZSCHE, F. Anotação póstuma 6[3], Fim de 1870. KSA 7, p. 130. Há aqui uma importante menção à correção feita na versão digital da edição crítica das obras de Nietzsche que está sendo coordenada por Paolo D'Iorio. No lugar de Ureinen-Wahren (realidade do Uno-primordial), consta, na KSA, Ureinen-Wesen (essência do Uno-primordial). 
há uma sensível diferença, para o autor, entre (i) a impotência do homem diante da essência da existência, (ii) a necessidade de se buscar lenitivo para a mesma na ilusão da arte e (iii) a promoção de um determinado valor cultural por meio do trágico. Ainda que essas três vertentes estejam intimamente interligadas, e principalmente que as duas últimas estejam subsumidas à primeira, é importante esclarecer que, mesmo considerando apenas o seu aspecto metafísico, há alguns fortes indícios de que a concepção de trágico do jovem Nietzsche extrapola sua interpretação da tragédia, conforme ficou comprovado pela recorrência às suas anotações pessoais do período. As análises subsequentes nos fornecerão subsídios suficientes para demonstrar essa tese, ainda não muito clara se levamos em conta apenas o aspecto metafísico do trágico.

\subsection{O aspecto propriamente filosófico}

A única forma de lidar com a realidade trágica da existência seria por meio da ilusão da arte? De acordo com Nietzsche, não. O exemplo histórico-filosófico de Sócrates ilustra paradigmaticamente a busca de um ideal alternativo ao da arte. E a análise nietzscheana do processo que culmina na sobrevalorização do conhecimento racional denota precisamente outro aspecto essencial do trágico em sua filosofia de juventude.

Ao final do capítulo 14 de $O$ nascimento da tragédia, o filósofo se pergunta "para onde aponta um fenômeno como o de Sócrates", dada a "tendência antidionisíaca" ${ }^{32}$ que atuara já antes dele. Essa questão se torna ainda mais significativa no momento em que, pouco adiante no texto, o autor se questiona se "de fato existe necessariamente, entre o socratismo e a arte, apenas uma relação antipódica" ${ }^{33}$. Nietzsche aponta, com isso, que há uma dubiedade (Bedenklichkeit), por parte do próprio Sócrates, "sobre os limites da natureza lógica": "será que não existe um reino da sabedoria, do qual a lógica está proscrita? Será que a arte não é até um correlativo necessário e um complemento da ciência?" 34 .

Essas reflexões fornecem subsídios para uma afirmação que causa espanto, à primeira vista: “(...) a influência de Sócrates (...) compeliu sempre à re-

\footnotetext{
${ }^{32}$ GT/NT 14. KSA 1, p. 95.

${ }^{33}$ GT/NT 14. KSA 1, p. 96. O autor está se referindo à experiência de Sócrates narrada no Fédon, 60d - 61c, na qual ele, ao ouvir a voz de seu daimon incitando-o a compor música, resolve transformar em versos algumas fábulas de Esopo. Essa passagem da primeira obra publicada de Nietzsche é, a meu ver, fundamental para a compreensão da amplitude do tema de Sócrates em seu pensamento de juventude. Tratei dessa questão em artigo cujas teses principais servem de base para a presente discussão sobre o estatuto do trágico no jovem Nietzsche. Cf.: DE PAULA, Wander Andrade. "Sócrates e a autossupressão do socratismo em 'O nascimento da tragédia". In: Cadernos Nietzsche, Guarulhos/Porto Seguro, v. 40, n. 1, p. 220-250, janeiro/abril, 2019.
}

${ }^{34}$ GT/NT 14. KSA 1, p. 96. 
criação da arte - e, na verdade, da arte no sentido mais profundo e lato, já metafísico - e, com a sua própria infinitude, também garantiu a infinitude desta" ${ }^{\prime 35}$. Nietzsche está preparando leitor, no meu modo de entender, para a concepção de que o processo ilusório de busca da verdade pela ciência, ao perceber os seus limites, leva à sua transmutação em arte:

(...) aquela inabalável fé de que o pensar, pelo fio condutor da causalidade, atinge até os abismos mais profundos do ser e que o pensar está em condições, não só de conhecê-lo, mas inclusive de corrigi-lo. Essa sublime ilusão metafísica é aditada como instinto à ciência, e a conduz sempre de novo a seus limites, onde ela tem de transmutar-se [umschlagen] em arte, que é o objetivo propriamente visado por esse mecanismo ${ }^{36}$.

A crença do homem socrático de que, por meio da ciência, a existência apareceria como conceituável e, portanto, justificada, encontra aqui o seu limite: de tal forma que o mito passa a ser não somente a "consequência necessária", mas sobretudo o "propósito" da ciência ${ }^{37}$. Trata-se do processo de esgotamento da ciência, por meio do desenvolvimento de sua lógica interna. A inevitabilidade que caracteriza tal processo parece dar ensejo à sua definição como trágico:

Mas agora a ciência, estimulada por sua poderosa ilusão, se dirige rápida e indetenível até os seus limites, nos quais naufraga seu otimismo oculto na essência da lógica. Pois a periferia do círculo da ciência possui infinitos pontos e, enquanto não for possível prever de maneira nenhuma como se poderá alguma vez medir completamente o círculo, o homem nobre e dotado, ainda antes de chegar ao meio de sua existência, tropeça, e de modo inevitável, em tais pontos fronteiriços da periferia, onde fixa o olhar no inesclarecível. Quando divisa aí, para seu susto, como, nesses limites, a lógica passa a girar em redor de si mesma e acaba por morder a própria cauda - então irrompe a nova forma de conhecimento, o conhecimento trágico [tragische Erkenntniss], que, mesmo para ser apenas suportado, precisa da arte como meio de proteção e remédio ${ }^{38}$.

Surge aqui, a partir de uma evidência textual explícita, uma concepção de trágico não imediatamente vinculada à condição essencial da existência enquanto contradição e sofrimento e à impotência do homem diante de tal condição, mas ao processo de "auto-esgotamento" da ciência. Trágica é a inevitabilidade, ou a necessidade, que concerne a esse processo - sobretudo por ser um processo de autodestruição, cujo protótipo Nietzsche encontra na figura de Sócrates ${ }^{39}$. O filósofo está rompendo aqui, no meu modo de entender, com a tradição alemã de interpretação do trágico, ao concebê-lo não somente sob seu aspecto metafísico, mas também sob o ponto de

${ }^{35}$ GT/NT, 15. KSA 1, p. 97.

${ }^{36}$ GT/NT, 15. KSA 1, p. 99.

${ }^{37}$ GT/NT, 15. KSA 1, p. 99

${ }^{38}$ GT/NT, 15. KSA 1, p. 101. Tr. de JG, com alterações.

${ }^{39}$ Cf. GT/NT, 15. KSA 1, p. 102. 
vista epistemológico, na medida em que trata dos limites do conhecimento racional e atribui ao processo que culmina com a sua transmutação em arte a alcunha 'conhecimento trágico'.

Nietzsche desenvolve esse aspecto do trágico em algumas anotações pessoais. Em uma delas, o autor vale-se da concepção de verdade como produto do conhecimento lógico para demonstrar que a consequência imediata de seu desenvolvimento é a reconciliação com a noção de "verdade" ou a "sabedoria" dionisíaca - e denomina esse processo como "trágico": "na cosmovisão de mundo [Weltanschauung] trágica o impulso à verdade e o impulso à sabedoria se reconciliaram. $\mathrm{O}$ desenvolvimento lógico os dissolveu e os forçou à criação da introvisão de mundo mística"40. Em outra anotação, ainda nesse sentido, o filósofo formula a questão do trágico do seguinte modo: "o objetivo da ciência que Sócrates inaugurou é o conhecimento trágico como preparação do gênio"41.

A figura de Sócrates significa para Nietzsche, portanto, bem mais que o instrumento de dissolução da cultura artística antiga. Creio ter boas razões para defender que Nietzsche esteja voluntariamente se valendo de imagens antagônicas do filósofo grego, a fim de demonstrar que a concepção de trágico está presente sobretudo em suas análises acerca do desenvolvimento da racionalidade ocidental. É nessa mesma esteira que o autor vincula as figuras do Sócrates musicante e do homem trágico, discutida anteriormente: "como Sócrates pode compor música? (...) A correção de mundo [Weltcorrektur] artística e científica. (...) O mecanismo de como a ciência se transmutou em arte. (...) O homem trágico. - O Sócrates musicante" ${ }^{\prime 2}$. O exemplo do Sócrates musicante disporia, portanto, do potencial educativo e emancipador conferido por Nietzsche ao homem trágico: é como se o fato de ter vivenciado até as últimas consequências a lógica da ciência lhe concedesse a prerrogativa de dispor de um conhecimento privilegiado da existência, conhecimento que o filósofo alemão denomina 'trágico'. Não se trata, portanto, nesse contexto, de uma interpretação meramente estética da existência. Nietzsche parece estar defendendo uma tese filosófica mais forte, cujos importantes desdobramentos para o seu pensamento posterior serão discutidos em termos de autossupressão do conhecimento, conforme será analisado adiante.

\footnotetext{
${ }^{40}$ NIETZSCHE, F. Anotação póstuma 5[110], Setembro de 1870 - Janeiro de 1871. KSA 7, p. 123.

${ }^{41}$ NIETZSCHE, F. Anotação póstuma 7[174], Fim de 1870 - Abril de 1871. KSA 7, p. 206.

${ }^{42}$ NIETZSCHE, F. Anotação póstuma 6[11], Fim de 1870. KSA 7, p. 133. Tal questão se repete em outra anotação posterior, na qual Nietzsche demonstra a mesma preocupação com a relação entre arte e ciência, e considera "a lógica como uma predisposição artística (...)". Aqui a relação de Sócrates com a arte parece ter ganhado contornos ainda mais nítidos, para o autor: "o homem trágico como o Sócrates musicante" (8[13], Inverno de 1870-71 - Outono de 1872. KSA 7, p. 224). Cf., ainda: 8[14] e 8[15] Inverno de 1870-71 - Outono de 1872. KSA 7, p. 225. Cf., por fim, as ocasiões em que a Empédocles cabe a alcunha de "homem trágico", movido pelo "impulso de saber" (Wissenstrieb): 5[94], Setembro de 1870 - Janeiro de 1871. KSA 7, p. 118; 7[101], Fim de 1870 - Abril de 1871 (KSA 7, p. 161).
} 
Kant e Schopenhauer teriam sido os pensadores que formularam conceitualmente esse processo, razão pela qual eles configuram, aos olhos de Nietzsche, a expressão filosófica moderna do conhecimento trágico:

(...) por meio de Kant e Schopenhauer, o espírito da filosofia alemã, manando de fontes idênticas, viu-se possibilitado a destruir o satisfeito prazer de existir do socratismo científico, pela demonstração de seus limites, e (...) através dessa demonstração se introduziu um modo infinitamente mais profundo e sério de considerar as questões éticas e a arte, modo que podemos designar francamente como a sabedoria dionisíaca expressa em conceitos (...) nós revivemos analogicamente em ordem inversa, por assim dizer, as grandes épocas principais do ser helênico, e agora, por exemplo, parecemos retroceder da era alexandrina para o período da tragédia ${ }^{43}$.

Cumpre destacar que, a despeito de uma possível desfaçatez de Nietzsche nessa descrição dos dois filósofos, o objetivo do autor nessa empreitada é a apresentação da era trágica moderna a partir de uma diferença fundamental em relação à época trágica dos gregos: ela é produto do esfacelamento e da transformação da ciência em arte, fenômeno desconhecido entre os gregos antigos. É a partir dessa ótica que Nietzsche concebe a cultura que ele denomina trágica. Se do "prazer socrático do conhecer" e da "ilusão de poder curar por seu intermédio a ferida eterna da existência" se origina a cultura socrática, e do "véu da beleza da arte" a artística, Kant e Schopenhauer teriam sido os filósofos que "conquistaram a vitória mais difícil, a vitória sobre o otimismo oculto na essência da lógica", substrato da cultura de sua época, dando origem à cultura trágica, cujo pressuposto é o "consolo metafísico de que, sob o turbilhão dos fenômenos, continua fluindo a vida eterna" ${ }^{44}$ e cuja "característica mais importante é que, para o lugar da ciência como alvo supremo, se empurra a sabedoria",

(..) a qual são iludida pelos sedutores desvios das ciências, volta-se com olhar fixo para a imagem conjunta do mundo, e com um sentimento simpático de amor procura apreender nela o eterno sofrimento como sofrimento próprio. (...) não seria necessário, porventura, que o homem trágico dessa cultura, na sua auto-educação para o sério e para o horror, devesse desejar uma nova arte, a arte do consolo metafísico, a tragédia? ${ }^{45}$.

O aspecto epistemológico do trágico denota, sobretudo, que o tema nem sempre está imediatamente vinculado, para o autor, ao problema da tragédia. $\mathrm{O}$ fato de Nietzsche lançar mão de uma análise de toda cultura ocidental a partir do fenômeno do socratismo é o que me permite pensar $\mathrm{o}$ aspecto epistemológico como o aspecto propriamente filosófico do trágico. A originalidade da leitura nietzscheana do trágico reside, portanto, em concebê-lo não apenas a partir da tragédia grega e porventura de outras manifestações artísticas, mas principalmente em transformá-lo em

${ }^{43}$ GT/NT, 19. KSA 1, p. 128.

${ }^{44}$ GT/NT, 18. KSA 1, p. 115.

${ }^{45}$ GT/NT, 18. KSA 1, p. 118-119. 
uma concepção-chave da sua leitura das origens e dos desdobramentos da cultura ocidental. Esse ponto de vista torna-se ainda mais claro quando Nietzsche trata da figura do "filósofo do conhecimento trágico", a qual antecipa várias discussões fundamentais de seu pensamento de maturidade.

\section{O trágico como autossupressão do esclarecimento filosófico}

Nietzsche trata do homem trágico, conforme discutido, a partir da concepção de que o gênio tem a capacidade de engendrar uma rede de ilusão artística, compreendida como benéfica para os propósitos culturais que o filósofo parece defender nesse período de sua produção. Educar para o gênio pressuporia, nesse sentido, não apenas considerar a contradição como marca distintiva da existência, mas, sobretudo, tornar necessária tal rede de ilusão artística. Essa discussão parece apresentar importantes desdobramentos nas anotações pessoais imediatamente posteriores à publicação de sua primeira obra. Ao tratar do "filósofo do conhecimento trágico", o enfoque de Nietzsche não recai tanto sobre uma apologia da ilusão artística, tal como engendrada pelo homem trágico, mas sobre o processo de autodestruição da ilusão científica, levado a cabo pelo desenvolvimento da própria pulsão de conhecimento:

O filósofo do conhecimento trágico. Ele domina a pulsão de saber [Wissenstrieb] desenfreada não por meio de uma nova metafísica. Ele não constitui nova crença alguma. Ele sente tragicamente que o fundamento da metafísica fora retirado e jamais pode se contentar com o colorido turbilhão de jogos [Wirbelspiele] das ciências. Ele constrói uma nova vida: ele devolve novamente à arte o seu direito.

O filósofo do conhecimento desesperado realizar-se-á em uma ciência cega: saber a todo preço.

Para o filósofo trágico, a imagem da existência se completa, quando o metafísico aparece apenas antropomorficamente. Ele não é cético.

Deve-se criar aqui um conceito: pois o ceticismo não é o objetivo. A pulsão de conhecimento [Erkenntnißtrieb], tendo alcançado os seus limites, volta-se contra si mesma para se tornar apenas crítica do saber. O conhecimento a serviço da melhor de todas as vidas.

Deve-se querer a ilusão - nisto consiste o trágico ${ }^{46}$.

O texto acima é significativo sob diversos pontos de vista. Em primeiro lugar, por se tratar de uma das poucas ocasiões em que Nietzsche, ainda que em uma anotação pessoal, define o trágico. Tal definição denota uma característica existencial básica da humanidade: trágica é a necessidade con-

${ }^{46}$ NIETZSCHE, F. Anotação póstuma 19[35], Verão de 1872 - Início de 1873. KSA 7, p. 427-8. 
cernente ao desejo de ilusão. Não há alternativa diante de tal necessidade, restando aos seres humanos encontrar as formas de ilusão mais adequadas às suas demandas. Em segundo lugar, porque recoloca a pergunta pelo lugar da ilusão na vida humana, desta vez sob o ponto de vista da ciência. A apologia da ilusão a que Nietzsche tantas vezes se refere em sua obra de juventude passa necessariamente, portanto, não apenas pelo elogio da arte, mas sobretudo pelo reconhecimento do caráter ilusório concernente também à própria ciência e pela avaliação de seu potencial de promoção da cultura ${ }^{47}$.

Não se trata, portanto, nesse contexto, de uma mera comparação entre formas de ilusão, com vistas a hierarquizá-las e mais uma vez reafirmar o caráter inigualável da ilusão artística, mas antes de demonstrar que essas formas de ilusão compartilham um solo comum, do qual se originam e se diversificam nas mais diversas formas de ilusão, cada qual com sua função e importância. Pode-se dizer que esse solo comum é a ideia de "necessidade metafísica" (metaphysiches Bedürfniss), que está na base da concepção de "justificação da existência" (Rechtfertigung des Daseins), problema fundamental que, conforme antecipado, concerne o pessimismo filosófico do século XIX e ao qual Nietzsche busca dar uma resposta com seu pensamento de juventude: a necessidade da ilusão é uma reverberação da necessidade de atribuição de sentido à existência. Trágica é, em última instância, a necessidade de atribuição de sentido à existência, conforme o autor sugere ao afirmar que a "necessidade mais profunda" diz respeito à "pergunta pelo valor da existência" 48 .

\footnotetext{
${ }^{47}$ Não podemos nos esquecer que Nietzsche, cerca de dois anos antes, havia escrito: "a maioria dos homens percebe ocasionalmente que eles vivem em uma rede de ilusões. Poucos, entretanto, reconhecem o quão distante essas ilusões alcançam. Não se deixar conduzir por ilusões é uma crença ingênua infinita, mas é o imperativo intelectual, o mandamento da ciência" (5[33], Setembro de 1870 - Janeiro de 1871, KSA 7, p. 101-2). Perceba-se como o autor, ao criticar a suposta prerrogativa científica de ser desprovida de toda e qualquer forma de ilusão, indica o potencial humano de criação de ilusões. É talvez nessa direção que ele afirma, alguns anos mais tarde: "ser completamente veraz [wahrhaftig] - magnífico desejo heroico do homem, em uma natureza enganosa! Mas possível somente de modo muito relativo! Isto é trágico. Este é o problema trágico de Kant! Agora a arte recebe uma dignidade completamente nova. As ciências, ao contrário, são degradadas em um grau" (19[104], Verão de 1872 - Início de 1873. KSA 7, p. 453-4). O caráter trágico da filosofia de Kant residiria precisamente na demonstração dos limites da pulsão de saber e na "resignação do conhecimento" (19[248], Verão de 1872 - Início de 1873. KSA 7, p. 497), o que implicaria em uma reformulação do estatuto da filosofia, como o próprio autor ensaia em diversas anotações do período: a filosofia é uma arte ou uma ciência? Qual é o seu parentesco com a religião? Cf. 19[62], Verão de 1872 - Início de 1873. KSA 7, p. 439. Cf., ainda, por exemplo, 19[126]. KSA 7, p. 459; 19[34]. KSA 7, p. 426-7.

${ }^{48}$ NIETZSCHE, F. Anotação póstuma 19[34], Verão de 1872 - Início de 1873. KSA 7, p. 427. Rogério Lopes defende que a concepção nietzscheana de conhecimento trágico está diretamente relacionada aos dois compromissos que o filósofo assume neste momento de sua produção: dar conta (i) das exigências da cultura e da vida em geral, tarefa esta relacionada à promoção da cultura e, por conseguinte, à justificação metafísica da existência; e (ii) das exigências da consciência intelectual, tarefa esta relacionada à suspensão do juízo em situações de indecidibilidade epistêmica, e que parece estar em contradição com os fins
} 
Há uma tese filosófica fundamental que subjaz às análises nietzscheanas do processo de esgotamento do conhecimento científico: trata-se da concepção de que todos os grandes processos histórico-culturais tendem a se autossuprimir por meio de uma espécie de ruptura interna, causada pelo desenvolvimento de sua própria lógica. Essa tese, que se torna mais conhecida nas reflexões nietzscheanas de maturidade sobre a moral, encontra nesse contexto um solo fértil para suas primeiras formulações. As discussões precedentes sobre os aspectos e as variantes do trágico no jovem Nietzsche corroboram, nesse sentido, a interpretação de Claus Zittel, para quem a autossupressão (Selbstaufhebung) é um princípio da "filosofia trágica" nietzscheana ${ }^{49}$. Tomando o termo como a estratégia crítica mais consequente e, sobretudo, como um conceito-chave de todo o pensamento de Nietzsche ${ }^{50}$, Zittel analisa as variações do conceito de autossupressão desde $O$ nascimento da tragédia. Especificamente no que diz respeito ao problema de que me ocupo, o autor busca demonstrar que o processo que levou ao suicídio da tragédia parte de si mesma: a ciência socrática não é produto de uma pulsão exterior e estranha à tragédia, mas é o desenvolvimento exacerbado da pulsão artística apolínea, que em sua metamorfose culmina no processo de autossupressão do socratismo e, em última instância, da própria cultura grega. O socratismo se

de edificação do primeiro compromisso. $\mathrm{O}$ autor reconhece que esta tensão está presente na primeira obra de Nietzsche, e muito especialmente em suas análises acerca do socratismo: “Nietzsche tenta executar este programa no Nascimento da Tragédia. A principal premissa histórica que sustenta este primeiro experimento filosófico de Nietzsche é a do esgotamento do socratismo. Pensado e vivido até suas últimas consequências, o ideal da vida teórica expõe aos seus adeptos a natureza ilusória de suas duas grandes convicções de base: a crença no caráter cognoscível do real e na possibilidade de reformar a existência mediante o conhecimento, ou seja, a crença no caráter terapêutico da teoria. Diante do impasse do ideal da vida teórica Nietzsche esboça um ideal alternativo, de retomada da visão de mundo trágica sob o comando da arte. A apologia da experiência estética esbarra entretanto na dificuldade de justificá-la frente à demanda, à primeira vista igualmente legítima, de outras esferas da experiência humana, tais como a da religião e da moral. Um fragmento datado do verão de 1872 - início de 1873 mostra que Nietzsche tem consciência da dificuldade de reivindicar um significado metafísico para qualquer destas dimensões da existência humana: 'Não se pode provar nem o significado metafísico, nem ético, nem estético da existência' (KSA, Vol. VII, p. 459)" (LOPES, Rogério Antônio. Ceticismo e vida contemplativa em Nietzsche. FAFICH-UFMG, Tese de Doutorado, 2008. P. 162, nota 121).

${ }^{49}$ ZITTEL, Klaus. Selbstaufhebungenfiguren bei Nietzsche. Würzburg, Alemanha: Königshausen und Neumann, 1993. Cf. p. 11.

${ }^{50}$ Uma importante reação ao trabalho de Zittel partiu do pesquisador brasileiro Oswaldo Giacoia Júnior. Ele destaca a seção 27 da terceira dissertação da Genealogia da moral como a passagem que denota a importância do conceito de autossupressão para o programa filosófico nietzscheano, e a partir dela discute suas principais modalizações, todas presentes no pensamento de maturidade do filósofo alemão: autossupressão da veracidade, da consciência moral, dos ideais ascéticos, do sentimento de culpa, do ressentimento, da vingança etc. (GIACÓIA JÚNIOR, Oswaldo. Nietzsche: o humano como memória e como promessa. Petrópolis, RJ: Vozes, 2013. Cf. pp. 118ss). Creio ter boas razões, entretanto, para defender que o tratamento dedicado por Nietzsche ao tema do trágico é comprovação suficiente de que esses problemas se encontram de certo modo inter-relacionados já em suas primeiras reflexões filosóficas. 
autossuprime, de acordo com o autor, pelo processo de autorreflexão do conhecimento que demonstra a incompatibilidade entre suas premissas e pretensões: pois, ao mesmo tempo em que defende um ideal bastante restrito de conhecimento, o socratismo almeja atribuir um sentido à existência, e até mesmo "corrigi-la". Esse processo de "absolutização" da tendência socrática, que busca estabilidade ao evitar o contraditório, culmina no reconhecimento do centro ilógico do universo. Daí a filosofia kantiana ser, para Nietzsche, em certo sentido trágica. Pois, ao invés de refundar o conhecimento científico como transcendental, ele conduz à sua autossupressão ${ }^{51}$.

O conceito de autossupressão figura como um componente teórico significativo, portanto, para a comprovação da amplitude do conceito de trágico no jovem Nietzsche, e indica, ademais, sua relevância para a concepção de filosofia do próprio autor: pensadas sob o ponto de vista do processo de autossupressão da ciência, as discussões nietzscheanas posteriores sobre a vontade de verdade e a autossupressão da moral, por exemplo, são de certo modo antecipadas e formuladas filosoficamente em sua obra de juventude, por meio do problema do trágico.

\section{Considerações finais}

As análises precedentes demonstraram que Nietzsche rompe, de antemão, com a tradição filosófica alemã que pensa o problema do trágico no século XIX, na medida em que amplia o escopo da discussão para além dos limites da estética, e muito especialmente da tragédia grega antiga. Sua interpretação do trágico toma como referência, sobretudo, as origens e os

${ }^{51}$ ZITTEL, Klaus. Selbstaufhebungenfiguren bei Nietzsche. Würzburg, Alemanha: Königshausen und Neumann, 1993. Cf. p. 22-35. Ao tratar do problema do inconsciente no jovem Nietzsche, William Mattioli defende posição semelhante, ao alertar que o socratismo é, em O nascimento da tragédia, uma espécie de sublimação da pulsão apolínea. O autor pretende demonstrar, com isso, que "o fenômeno da morte da tragédia deve ser descrito antes de tudo como uma ruptura interna, ocasionada por um componente pertencente ao mesmo conjunto de forças que constituem o seu núcleo criativo. A afirmação de que a tragédia morreu por suicídio não significa simplesmente que ela veio a óbito pelas mãos de um tragediógrafo, mas que o impulso que a assassinou é um rebento daqueles mesmos impulsos que a constituíram (...). A imagem do Sócrates musicante representa muito bem o imbricamento desses impulsos. A possibilidade de um Sócrates artístico depende do enraizamento do socratismo no mesmo complexo pulsional que constitui o apolíneo, o dionisíaco e, por conseguinte, o amálgama dessas duas forças. Nascido como expressão difrativa e autofágica de um impulso artístico, o princípio socrático finalmente retorna à sua origem primeira ao se converter novamente em princípio estético, ao dar lugar, no âmbito do desenvolvimento da cultura, ao movimento de transfiguração da ciência em arte e tornar novamente possível, pelas vias da experiência do trágico, a satisfação do impulso fundamental que estava em sua base: o impulso metafísico" (MATTIOLI, 2016, p. 217-218). 
desdobramentos da cultura ocidental, da qual a filosofia é uma herdeira direta. Ao tratar do processo de esgotamento do socratismo como fruto do desenvolvimento de sua própria lógica interna, via autossupressão, e denominá-lo também como trágico, o filósofo indica que o cerne do problema se encontra na necessidade humana de atribuição de sentido à existência: arte, ciência e religião nada mais seriam, portanto, que manifestações dessa necessidade, consubstanciadas em formas de cultura. A cultura propriamente trágica é, nesse sentido, tal como o autor faz entender no capítulo 18 de $O$ nascimento da tragédia, a budista, e não a helênico-artística ou a socrático-alexandrina, pois assume como seu pressuposto o problema dos limites humanos e da sua consequente necessidade de recurso à ilusão, problema esse que constitui o estofo, não declarado, tanto da tragédia grega antiga quanto do próprio socratismo ${ }^{52}$.

Creio ter razões suficientes, portanto, para afirmar que a interpretação nietzscheana do trágico na sua obra de juventude está diretamente vinculada à sua leitura do problema do esclarecimento filosófico, tal como reconhecem posteriormente em suas obras Adorno, Horkheimer e Habermas, ao tratarem da relação de íntima pertença entre mito e razão ${ }^{53}$. Nietzsche parece estar, de fato, bastante engajado em demonstrar que há uma espécie de solo comum, de onde surgem as principais manifestações culturais da humanidade. Espero ter demonstrado que o trágico é o conceito-chave para compreender o modo com que o filósofo não apenas leva a cabo uma análise bastante particular do processo de formação da cultura ocidental, mas também, e sobretudo, começa a desenvolver a sua própria concepção de filosofia.

\section{Referências bibliográficas}

ADORNO, Theodor;; HORKHEIMER, Max. Dialética do esclarecimento. Tradução de Guido Antônio de Almeida. Rio de Janeiro: Jorge Zahar, 1985.

ARALDI, Clademir. O conflito trágico entre arte e verdade no pensamento de Nietzsche. In: Revista Trágica, 2o semestre de 2008 (n. 2), p. 37-52.

ARISTÓTELES. Poética. Tradução de Paulo Pinheiro. São Paulo: Editora 34, 2015.

\footnotetext{
${ }^{52}$ Enrico Müller, ainda que trate da noção de trágico em Nietzsche fundamentalmente a partir de sua interpretação da tragédia, parece defender tese semelhante, ao tratar do "êxtase", que para o filósofo acompanha a "sabedoria dionisíaca": tal sentimento demarca precisamente, para o filósofo alemão, a percepção humana dos limites enquanto limites (MÜLLER, Enrico. Die Griechen im Denken Nietzsches. Berlin/New York: Walter de Gruyter, 2005 [Monographien und Texte zur Nietzsche-Forschung, Band 50]. Cf. p. 52-54).

${ }^{53}$ Cf. ADORNO, Theodor.; HORKHEIMER, Max. Dialética do esclarecimento. Tradução de Guido Antônio de Almeida. Rio de Janeiro: Jorge Zahar, 1985; HABERMAS, Jürgen. O discurso filosófico da modernidade: doze lições. Tradução de Luiz Sérgio Repa e Rodnei Nascimento. São Paulo: Martins Fontes, 2000.
} 
DAHLKVIST, Tobias. Nietzsche and the Philosophy of Pessimism. A study of Nietzsche's Relation to the Pessimistic Tradition: Schopenhauer, Hartmann, Leopardi. Uppsala: Uppsala Studies in History of Ideas 35, 2007.

DE PAULA, Wander Andrade. $O(s)$ Sócrates de Nietzsche: uma leitura d'O nascimento da tragédia, de Friedrich Nietzsche. Dissertação de Mestrado. Campinas: Universidade Estadual de Campinas, 2009.

- Nietzsche e a transfiguração do pessimismo schopenhaueriano. A concepção de filosofia trágica. Tese de Doutorado. Campinas: Universidade Estadual de Campinas, 2013.

. "Sócrates e a autossupressão do socratismo em O nascimento da tragédia". In: Cadernos Nietzsche, Guarulhos/Porto Seguro, v.40, n.1, p. 220-250, janeiro/abril, 2019.

GERHARDT, V. Pessimismus. In: Historisches Wörterbuch der Philosophie, Bd. 7: P-Q. Hrg. von Joachim Ritter et all. Basel und Darmstadt, 1989a. Col. 386-395.

Sinn des Lebens. In: Historisches Wörterbuch der Philosophie, vol. 9: Se-Sp. Hrg. von Joachim Ritter et all. Basel und Darmstadt, 1989b. Col. 815-824.

GIACÓIA JÚNIOR, Oswaldo. Nietzsche: o humano como memória e como promessa. Petrópolis, RJ: Vozes, 2013.

HABERMAS, Jürgen. O discurso filosófico da modernidade: doze lições. Tradução de Luiz Sérgio Repa e Rodnei Nascimento. São Paulo: Martins Fontes, 2000.

LESKY, A. A tragédia grega. Tradução de J. Guinsburg. São Paulo: Perspectiva, 2006.

LOOCK, R. Tragische. In: Historisches Wörterbuch der Philosophie, Bd. 10: St-T. Hrg. von Joachim Ritter et all. Basel: Schwabe, 1998. Col. 1334-1345.

LOPES, Rogério Antônio. Ceticismo e vida contemplativa em Nietzsche. FAFICH-UFMG, Tese de Doutorado, 2008.

MACHADO, Roberto. O Nascimento do Trágico: de Schiller a Nietzsche. Rio de Janeiro: Jorge Zahar, 2006.

MATTIOLI, William. O inconsciente no jovem Nietzsche: da intencionalidade das formas naturais à vida na linguagem. FAFICH-UFMG, Tese de Doutorado, 2016.

MITCHELL, R. Melancholy. In: Encyclopedia of the Romantic Era, 1760-1850. Vol. II. Ed. Ch. J. Murray. New York;London: Fitzroy Dearborn, p. 722-723.

MÜLLER, Enrico. Die Griechen im Denken Nietzsches. Berlin/New York: Walter de Gruyter, 2005 (Monographien und Texte zur Nietzsche-Forschung, Band 50).

NABAIS, Nuno. Metafísica do trágico. Estudos sobre Nietzsche. Lisboa: Relógio D'Água, 1997.

NIETZSCHE, Friedrich. Sämtliche Werke. Kritische Studienausgabe (KSA: 15 vols.). Hrsg. von G. Colli und M. Montinari. Berlin/New York: de Gruyter, 1988.

O nascimento da tragédia: ou Helenismo e Pessimismo. Tradução de J. Guinsburg. São Paulo: Companhia das Letras, 1992.

PAUEN, Michael. Pessimismus. Geschichtsphilosophie, Metaphysik und Moderne von Nietzsche bis Spengler. Berlin: Akademir Verlag, 1997. 
ROMILLY, J. A tragédia grega. Tradução de Leonor Santa Bárbara. Lisboa, Portugal: Edições 70, 2013.

SAFRANSKI, Rüdiger. Romantismo: uma questão alemã. Tradução de Rita Rios. São Paulo: Estação Liberdade, 2010.

SILK, M. S; STERN, J. P. Nietzsche on tragedy. New York: Cambridge University Press, 1981.

SZONDI, P. Ensaio sobre o trágico. Tradução de Pedro Süssekind. Rio de Janeiro: Jorge Zahar, 2004.

ZITTEL, Klaus. Selbstaufhebungenfiguren bei Nietzsche. Würzburg, Alemanha: Königshausen und Neumann, 1993.

Endereço do Autor:

Rua Laurentino Proença Filho, 300, 502A

Jardim da Penha

29060-440 Vitória - ES

wanderdepaula@gmail.com 